\title{
Structural Optimization of Wavy FinFET for Leakage Reduction and Performance Enhancement
}

\author{
Anju Chakkikavil ${ }^{*},{ }^{1}$, Nisha Kuruvilla ${ }^{1}$, Ayoob Khan ${ }^{1}$, Shahul Hameed ${ }^{2}$ \\ ${ }^{1}$ Department of Electronics Engineering, College of Engineering Chengannur, 689121, India \\ ${ }^{2}$ Department of Electronics and Communication Engineering, TKM College of Engineering, 691005, India
}

\begin{tabular}{l} 
A R T I C L E I \\
\hline Article history: \\
Received: 05 Ap \\
Accepted: 24 May, \\
Online: 30 June, \\
\hline Keywords: \\
FinFET \\
Ultrathin Body \\
Wavy \\
SOI \\
Leakage \\
Spacer
\end{tabular}

\section{Introduction}

Gordon Moore predicted the scaling trends in integrated circuits in 1965 [1]. The technology driving factors are reduced cost, improved performance and greater circuit functionality. Scaling causes reduction in gate control over current flow in channel and which will in turn results in short channel effects. In order to mitigate these effects, engineers had to innovate advanced MOSFET structures which can be used in smaller technology nodes. Gate oxide scaling combined with gate length scaling was the traditional MOSFET scaling which ran out in the early 2000's due to leakage limitations. Engineers had to innovate new structures since market was demanding low leakage. Strained silicon is an example of a revolutionary technology that provided improved performance when traditional MOSFET scaling methods were no longer effective [2]. It provided valuable performance enhancements at $90 \mathrm{~nm}$ and $65 \mathrm{~nm}$ generations. Intel's $45 \mathrm{~nm}$ logic technology was the first to introduce high- $\mathrm{k}+$

\footnotetext{
* Anju Chakkikavil, Department of Electronics Engineering, College of Engineering Chengannur, 689121, India | Email: anjucraman@gmail.com
}

metal gate transistors for improved performance and reduced leakage [3]. Further scaling was achieved using structural change in transistor architecture. A layered silicon-insulator-silicon substrate replaced conventional silicon substrates to form SOI technology[4]. The ultrathin body FET eliminates the leakage paths between source and drain, and thereby control shortchannel effects with thin body [5]. Multiple gate devices such as double gate, trigate, pi-gate, GAA devices could achieve better gate control over channel [6]. ITFET (Inverted T channel FET) combines double gate FinFET and single gate SOI to achieve layout efficiency[7].

Wavy FinFET is a hybrid device comprising of FinFET and Ultrathin body FETs [8]. Since UTB (Ultrathin Body) is inserted in the otherwise wasted fin-fin spacing, drivability increases (because of the increased path for current flow ) without causing area penalty. The major issues related to wavy FinFET architecture are increase in leakage and reduction in threshold voltage. Optimization are required to mitigate these problems and thereby to obtain better device performance.

\begin{abstract}
A B S T R A C T technologies on SOI platform to provide high density and drivability without causing area voltage. This problem can be solved by structural modification of the device. This work analyses the performance of Wavy FinFET under various optimization methods such as device/channel engineering, work function engineering, spacer engineering and variation of isolation oxide thickness. The obtained results indicate that optimized Wavy FinFET can
act as a solution for low power, highly reliable device topology. Leakage power is found to be reduced by 40.39\%, 30.39\% and 43.75\% with channel engineering techniques such as
substrate doping., halo doping and retrograde doping, respectively. Leakage power is lowered by $35.48 \%$ and $32.25 \%$ with increase in gate work function and isolation oxide thickness respectively. By using high $k$ spacer material $54.77 \%$ reduction in leakage is further obtained without compromising drive current. In ADSE(Asymmetric Drain Side
Extention) wavy FinFET, leakage is reduced by $61.35 \%$. Whereas in symmetric and asymmetric Dual $k$ wavy FinFET, leakage reduction is found to be $44.19 \%$ and $28.25 \%$ respectively.
\end{abstract}


In the following session, comparative analysis of trigate SOI FinFET and wavy FinFET are done. After that optimization methods such as channel engineering, work function engineering, spacer engineering and isolation oxide thickness variation are done. Finally the last session concludes this work.

\section{Trigate v/s Wavy FinFET}

3D structure of Trigate SOI FinFET, segmented trigate SOI FinFET with 3 fins and wavy FinFET having dimensions as per 2013 Overall Roadmap Technology Characteristics Fin-FET parameters specified by the International Technology Roadmap for Semiconductors (ITRS) at the 7-nm technology node [9] were drawn using COGENDA TCAD [10]. In all structures fin height width and fin termination edge are $30 \mathrm{~nm}, 6.8 \mathrm{~nm}$ and $25 \mathrm{~nm}$ respectively. Gate length is $18 \mathrm{~nm}$ and EOT is $0.5 \mathrm{~nm}$. The channel is intrinsic and UTB thickness in wavy FinFET is $4.5 \mathrm{~nm}$. Fin spacing is $19 \mathrm{~nm}$ in the case of multifin architecture. The structures are given in Figure 1. It can be seen that Ultrathin body is inserted in the otherwise wasted fin spacing to achieve advantages of two competing technologies. Figure 2 shows the gate cross section of trigate FinFET with single fin, with 3 fins and that of wavy FinFET. We can see that channel area under gate in wavy FinFET is higher compared to that of conventional FinFET.
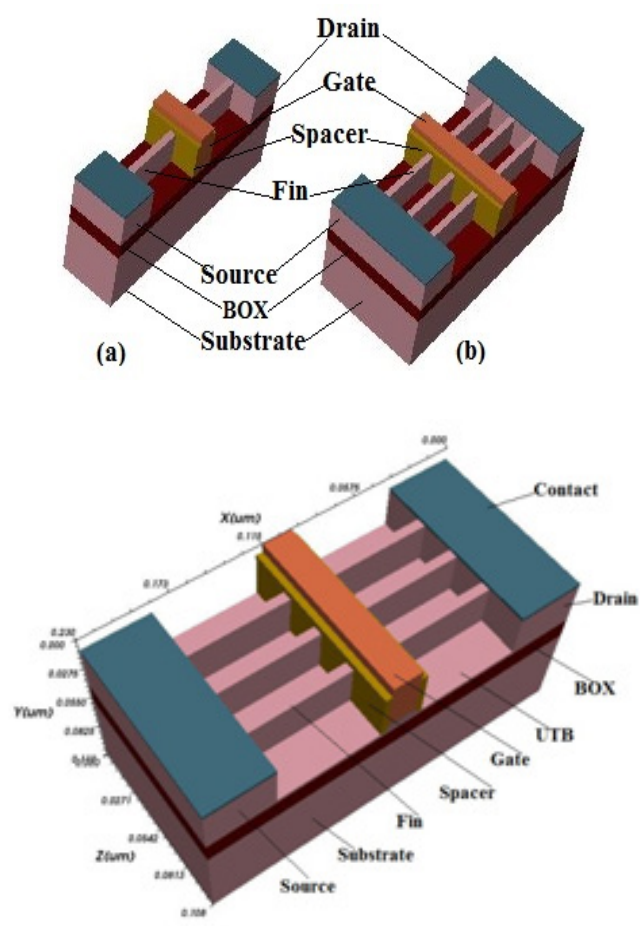

(c)

Figure 1.(a) Trigate FinFET with single fin, (b) Trigate FinFET with 3 fins, (c) Wavy FinFET

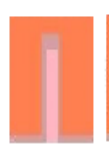

(a)

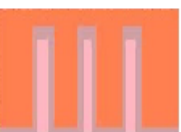

(b)

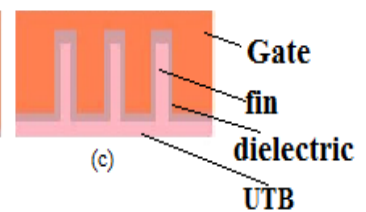

Figure 2. Gate cross section of (a) Trigate FinFET with single fin, (b) Trigate FinFET with 3 fins and (c) Wavy FinFET
Simulations are carried out to analyase the performance of normal trigate FinFET with single fin, trigate FinFET with multiple fins and wavy FinFET. Also the Ultrathin body thickness is varied from $2.5 \mathrm{~nm}$ to $4.5 \mathrm{~nm}$ to see the variation of current with ultrathin body thickness. In Table 1, W2.5, W3.5, W4.5 represents wavy FinFET with UTB thickness $2.5 \mathrm{~nm}, 3.5 \mathrm{~nm}, 4.5 \mathrm{~nm}$ respectively.

Table 1. Comparison of conventional FinFET and wavy FinFET (UTB thickness $=2.5 \mathrm{~nm}, 3.5 \mathrm{~nm}, 4.5 \mathrm{~nm}$ )

\begin{tabular}{|l|l|l|l|l|l|}
\hline $\begin{array}{l}\text { Stru } \\
\text { Cture }\end{array}$ & $\begin{array}{l}\mathrm{I}_{\text {off }} \\
(\mathrm{A})\end{array}$ & $\begin{array}{l}\mathrm{I}_{\text {on }} \\
(\mathrm{A})\end{array}$ & $\begin{array}{l}\mathrm{V}_{\mathrm{t}} \\
(\mathrm{m} \\
\mathrm{V})\end{array}$ & $\begin{array}{l}\mathrm{SS} \\
(\mathrm{m} \\
\mathrm{V} / \mathrm{d} \\
\mathrm{ec})\end{array}$ & $\begin{array}{l}\text { DIB } \\
\mathrm{L}\end{array}$ \\
\hline $\begin{array}{l}\text { trigate } \\
1 \text { fin }\end{array}$ & $2.05 \mathrm{e}-13$ & $1.03 \mathrm{e}-05$ & 372 & 62 & 40 \\
\hline $\begin{array}{l}\text { trigate } \\
\text { 3 fins }\end{array}$ & $3.21 \mathrm{e}-13$ & $2.43 \mathrm{e}-05$ & 371 & 62.8 & 40.2 \\
\hline W 2.5 & $1.09 \mathrm{e}-12$ & $2.79 \mathrm{e}-05$ & 367 & 65.7 & 43.6 \\
\hline W 3.5 & $3.35 \mathrm{e}-12$ & $2.95 \mathrm{e}-05$ & 365 & 70.2 & 47.3 \\
\hline W 4.5 & $1.55 \mathrm{e}-11$ & $3.82 \mathrm{e}-05$ & 355 & 73.9 & 53 \\
\hline
\end{tabular}

It can be seen that the drive performance of segmented FinFET is better than that of conventional FinFET. In order to increase the drive current further, it is required to array more number of fins which will result in area penalty. At the same time wavy FinFET overcomes this difficulty and current is increased keeping the same footprint area. Also it is found that drive capability and short channel characteristics varies with the thickness of UTB in wavy FinFET. It can be seen that, higher UTB thickness results in $\mathrm{I}_{\mathrm{ON}}$. But the problem is along with $\mathrm{ON}$ current, OFF current also increases. Threshold voltage of wavy FinFET is lesser compared to that of conventional FinFET which further reduces with increase in UTB thickness.

Due to threshold voltage mismatch between UTB and fins, subthreshold swing and DIBL becomes higher in wavy channel transistor. Hence wavy FinFET has to be optimized to achieve higher ION with lower leakage power.

\section{Optimized Low Power Wavy FinFET}

Substrate back biasing is one of the methods for threshold voltage tuning [8]. Reverse back biasing helps to increase the $V_{t}$ and reduce $\mathrm{I}_{\mathrm{OFF}}$. The problem here is that the reduction in leakage is obtained at the expense of ON current. Hence another methods are needed to optimize wavy FinFET, which is discussed in the following sessions of this work.

\subsection{Substrate Doping}

Doping concentration of the silicon is varied from undoped to $1 \mathrm{e} 17 \mathrm{~cm}^{-3}$. Fig. 3 represents the variation in $V_{t}$ with doping concentration. $\mathrm{V}_{\mathrm{t}}$ increases as doping increases. Table 2 represents the effect of doping on $\mathrm{I}_{\mathrm{ON}}, \mathrm{I}_{\mathrm{OFF}}$ and leakage power. Both linear and logarithmic plot of $\mathrm{V}_{\mathrm{gs}}-\mathrm{I}_{\mathrm{d}}$ characteristics with different doping concentration are shown in Figure 4. It can be observed that along with increase in doping concentration, leakage is reduced. Hence leakage power is also reduced. $40.39 \%$ reduction in leakage current is obtained by choosing the doping concentration to be $1 \mathrm{e} 17 / \mathrm{cm}^{3}$. Here a $4.71 \%$ reduction in $\mathrm{ON}$ current is observed. 
Table 2. Effect of doping

\begin{tabular}{|l|l|l|l|}
\hline $\begin{array}{l}\text { Doping } \\
\left(\mathrm{cm}^{-3}\right)\end{array}$ & $\begin{array}{l}\mathrm{I}_{\text {off }} \\
\text { (A) }\end{array}$ & $\begin{array}{l}\mathrm{I}_{\text {on }} \\
\text { (A) }\end{array}$ & $\begin{array}{l}\text { Pleak } \\
\text { (W) }\end{array}$ \\
\hline Undoped & $1.55 \mathrm{e}-11$ & $3.82 \mathrm{e}-05$ & $1.24 \mathrm{e}-11$ \\
\hline $1 \mathrm{e} 16$ & $9.79 \mathrm{e}-12$ & $3.67 \mathrm{e}-05$ & $7.83 \mathrm{e}-12$ \\
\hline $1 \mathrm{e} 17$ & $9.24 \mathrm{e}-12$ & $3.64 \mathrm{e}-05$ & $7.39 \mathrm{e}-12$ \\
\hline
\end{tabular}

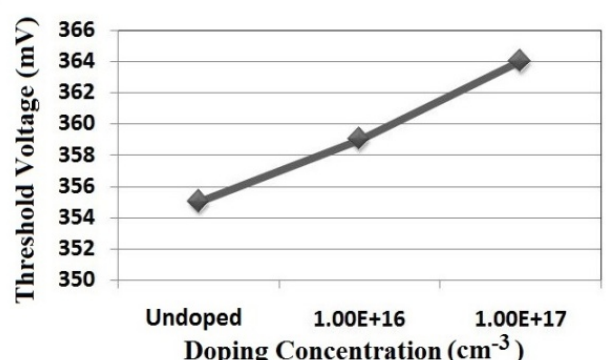

Figure $3 . \mathrm{V}_{\mathrm{t}}$ variation with doping concentration

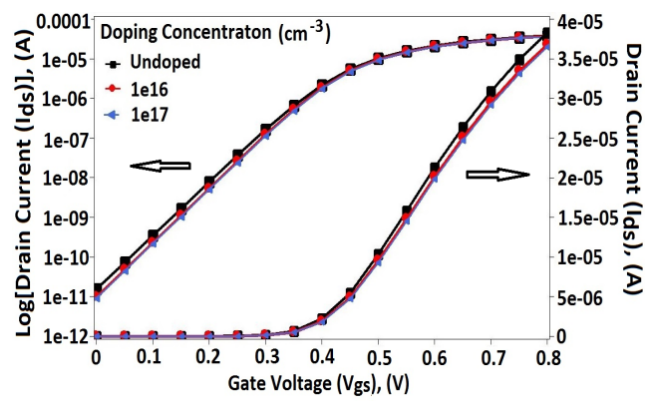

Figure 4. Transfer characteristics with different doping concentration

\subsection{Halo and Retrograde Doping}

Halo doping can be performed by incorporating highly doped $\mathrm{p}$ type region near source and drain ends. Here the drain and source junction depletion region width reduces. It can help in the reduction of DIBL (Drain Induced Barrier Lowering) and punch through. For retrograde doping surface concentration is kept low to increase surface mobility and the subsurface doping is kept high to act as a barrier against punch through [11]. Effect of both halo doping and retrograde doping are shown in Figure 5 and Table 3. By using these methods leakage can be reduced.

Table 3. effect of halo and retrograde doping

\begin{tabular}{|l|c|l|l|}
\hline & undoped & $\begin{array}{l}\text { Halo } \\
\text { doping }\end{array}$ & $\begin{array}{l}\text { Retrograde } \\
\text { Doping }\end{array}$ \\
\hline $\mathrm{I}_{\text {off }}$ & $1.55 \mathrm{e}-11$ & $1.079 \mathrm{e}-11$ & $8.718 \mathrm{e}-12$ \\
\hline $\mathrm{I}_{\text {on }}$ & $3.82 \mathrm{e}-05$ & $3.72 \mathrm{e}-05$ & $3.696 \mathrm{e}-05$ \\
\hline $\mathrm{P}_{\text {leak }}$ & $1.24 \mathrm{e}-11$ & $8.632 \mathrm{e}-12$ & $6.968 \mathrm{e}-12$ \\
\hline DIBL & 53 & 48 & 45.8 \\
\hline
\end{tabular}

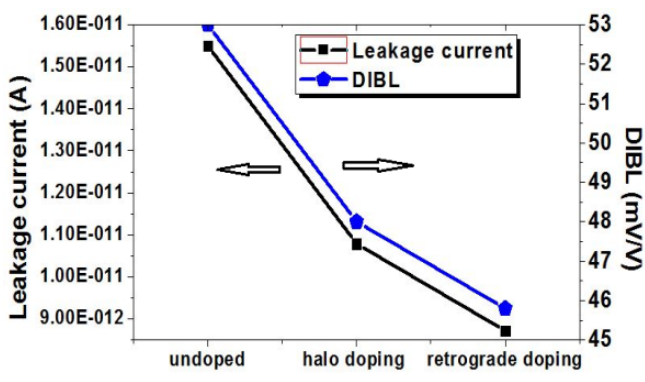

Figure 5. Effect of Halo and retrograde doping
Here the advantage is that we get reduction in leakage power without much sacrificing drive performance. Ion/Ioff ratio also will be higher.

\subsection{Work function Engineering}

Threshold voltage is dependent work function. Hence by varying gate work function of wavy FinFET, better performance can be achieved. Gate work function is varied from $4.5 \mathrm{eV}$ to 4.6 $\mathrm{eV}$. Effect of work function is shown in Figure 6 and Table 4. As the work function increases, threshold voltage increases and leakage reduces. $35.48 \%$ reduction in leakage power is obtained by increasing work function to $4.6 \mathrm{eV}$.

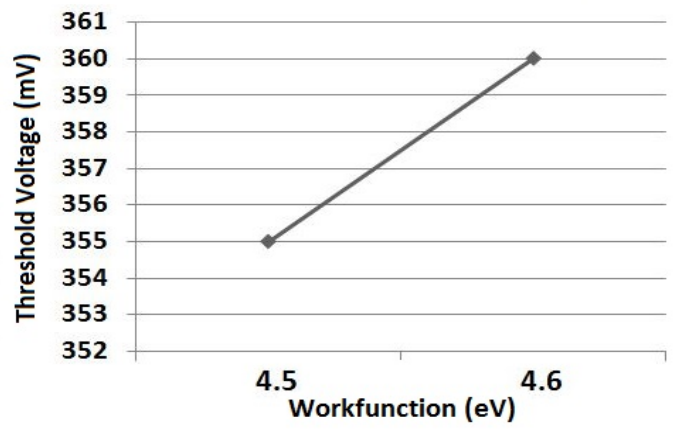

Figure 6. Effect of work function on $\mathrm{V}_{\mathrm{t}}$

Table 4. Effect of work function on performance of wavy FinFET

\begin{tabular}{|l|l|l|l|l|}
\hline $\begin{array}{l}\text { Work } \\
\text { Functi } \\
\text { on }(\mathrm{eV})\end{array}$ & $\mathrm{I}_{\text {off }}(\mathrm{A})$ & $\mathrm{I}_{\text {on }}(\mathrm{A})$ & $\begin{array}{l}\mathrm{V}_{\mathrm{t}} \\
(\mathrm{mV})\end{array}$ & $\mathrm{P}_{\text {leak }}(\mathrm{W})$ \\
\hline 4.5 & $1.55 \mathrm{e}-11$ & $3.82 \mathrm{e}-05$ & 355 & $1.24 \mathrm{e}-11$ \\
\hline 4.6 & $1.00 \mathrm{e}-11$ & $3.73 \mathrm{e}-05$ & 360 & $8.00 \mathrm{e}-12$ \\
\hline
\end{tabular}

\subsection{Isolation oxide thickness variation}

This is a method for leakage suppression. Threshold voltage is directly proportional to isolation oxide thickness. Increasing isolation oxide thickness leads to higher threshold voltage which further leads to reduced leakage. Isolation oxide thickness is varied from $20 \mathrm{~nm}$ to $40 \mathrm{~nm}$. Effect of BOX thickness variation is given in Figure 7. Leakage power is found to be lower in the case of higher oxide thickness.

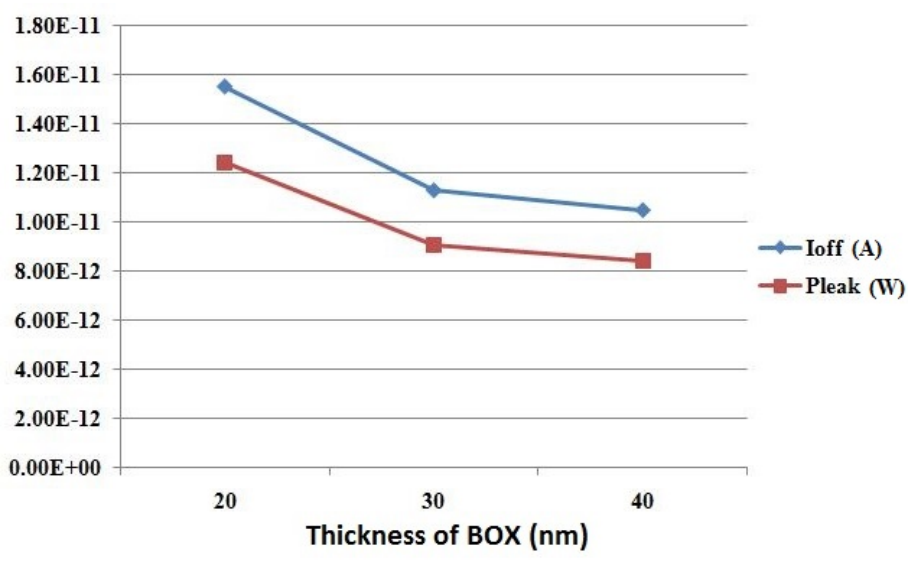

Figure 7. Effect of isolation oxide thickness on $\mathrm{I}_{\text {off }}$ and leakage power 


\subsection{High-k Spacer}

In sub-20 nm region, short channel effects are reduced using underlap regions. But here on current reduces. Even at high Vds, gate-source/drain barrier restricts source to drain carrier flow. Introduction of high-k spacers can provide strong field coupling from the gate. Effect change in spacer material is checked by using $\mathrm{SiO}_{2}(\mathrm{k}=3.9), \mathrm{Si}_{3} \mathrm{~N}_{4}(\mathrm{k}=7.5)$ and $\mathrm{Hfo}_{2}(\mathrm{k}=22)$ as the spacers. Simulation result is shown in Figure 8. As the dielectric constant of the spacer material increases, an increase in $\mathrm{I}_{\text {on }}$ and reduction in $\mathrm{I}_{\text {off }}$ can be seen. And thus device can be optimized for lower leakage power and higher $\mathrm{I}_{\text {on }} / \mathrm{I}_{\text {off }}$ ratio. Effect of change in spacer material on $\mathrm{I}_{\mathrm{off}}, \mathrm{I}_{\mathrm{on}}, \mathrm{V}_{\mathrm{t}}$ and leakage power is shown in Table 5.

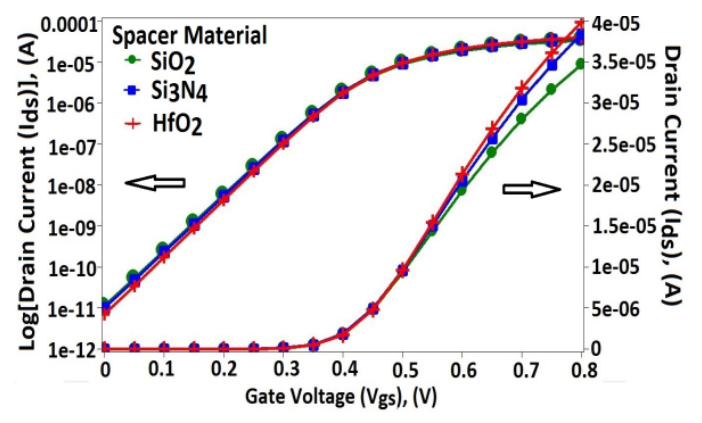

Figure 8. Transfer characteristics of wavy FinFET with different spacer materials

Table 5. Effect of change in spacer material

\begin{tabular}{|l|l|l|l|l|}
\hline $\begin{array}{l}\text { Mater } \\
\text { ial }\end{array}$ & I off(A) & Ion(A) & $\begin{array}{l}\mathrm{V}_{\mathrm{t}}(\mathrm{m} \\
\mathrm{V})\end{array}$ & Pleak \\
\hline $\mathrm{SiO}_{2}$ & $1.09 \mathrm{e}-11$ & $3.46 \mathrm{e}-05$ & 356 & $8.72 \mathrm{e}-12$ \\
\hline $\mathrm{Si}_{3} \mathrm{~N}_{4}$ & $1.01 \mathrm{e}-11$ & $3.84 \mathrm{e}-05$ & 362 & $8.08 \mathrm{e}-12$ \\
\hline $\mathrm{HfO}_{2}$ & $7.01 \mathrm{e}-12$ & $3.98 \mathrm{e}-05$ & 396 & $5.61 \mathrm{e}-12$ \\
\hline
\end{tabular}

Higher the dielectric strength of spacer, lesser the leakage, and higher the threshold voltage can be obtained which leads to a better device performance. By using $\mathrm{HfO} 2$ as the spacer material on both sides of gate, $54.77 \%$ reduction in off current is achieved.

\subsection{Asymmetric Drain Spacer Extention (ADSE) Wavy FinFET}

In asymmetric drain spacer extention FinFET as shown in Figure 9, an additional spacer is introduced only on the drain side to introduce drain-side underlap in FinFET. Thus, bidirectional currents in these transistors are not the same. The spacer thickness at drain side is higher which will result in asymmetry in current and reduction in DIBL. DIBL and OFF current is found to be reduced by using ADSE structure.

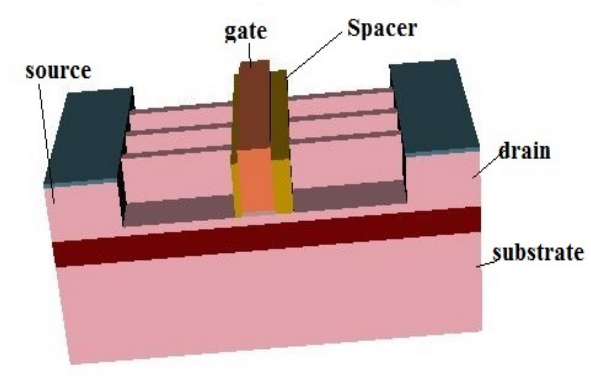

Figure 9: ADSE Wavy FinFET

Effect of ADSE wavy FinFET on drain current is shown in Figure 10. Drain current in logarithmic scale is shown on left $Y$

www.astesj.com axis and from which it can be understood that the OFF current is lower in ADSE Wavy FinFET compared to normal wavy FinFET. Here the leakage power is reduced by $61.35 \%$ compared to that of normal wavy FinFET.

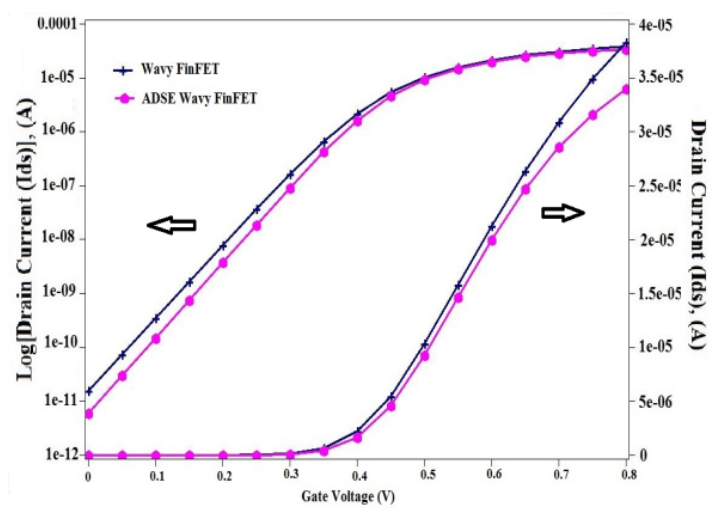

Figure 10: Effect of ADSE Wavy FinFET

\subsection{Symmetric and Asymmetric Dual-k Spacer Architecture}

The problem associated with high-k spacer is that it increases the fringe capacitance $\left(\mathrm{C}_{\mathrm{fr}}\right)$ that worsens the circuit delay in digital applications [12]. By introducing dual $\mathrm{k}$ spacer, instead of single spacer material, inner high-k and outer low-k spacer material is introduced. Interface region between high- $\mathrm{k}$ and low $\mathrm{k}$ region can make significant changes in device properties. Ion/Ioff can be increased.

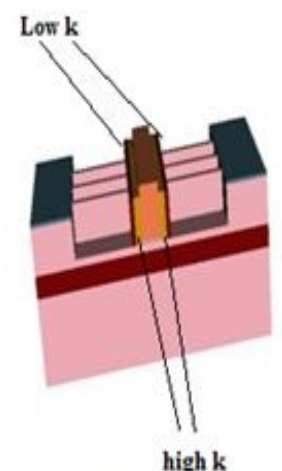

(a)

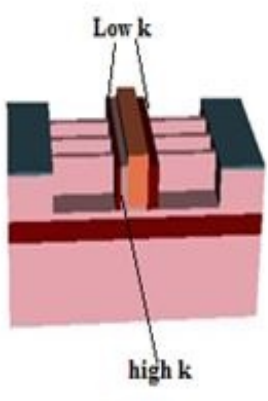

(b)
Figure 11: (a)Symmetric dual-k and(b)asymmetrc dual-k wavy FinFET.

In symmetric dual-k as shown in Figure 11(a), there will be dual $\mathrm{k}$ spacer on both sides of gate. Where as in asymmetric dual $\mathrm{k}$ structure as shown in Figure 11(b), dual k spacer is present only on source side. Effect of introducing symmetric dual-k spacer on leakage power and Ion/Ioff ratio are shown in Figure 12. For dualk, Si3N4 and $\mathrm{HfO} 2$ are used as high k spacers along with $\mathrm{SiO} 2$ spacer. $44.948 \%$ increase in I $\mathrm{I}_{\mathrm{N}} / \mathrm{I}_{\mathrm{OFF}}$ is obtained with symmetric dual-k structure (HfO2- inner high-k spacer) compared to conventional with $\mathrm{SiO} 2$ spacer. 


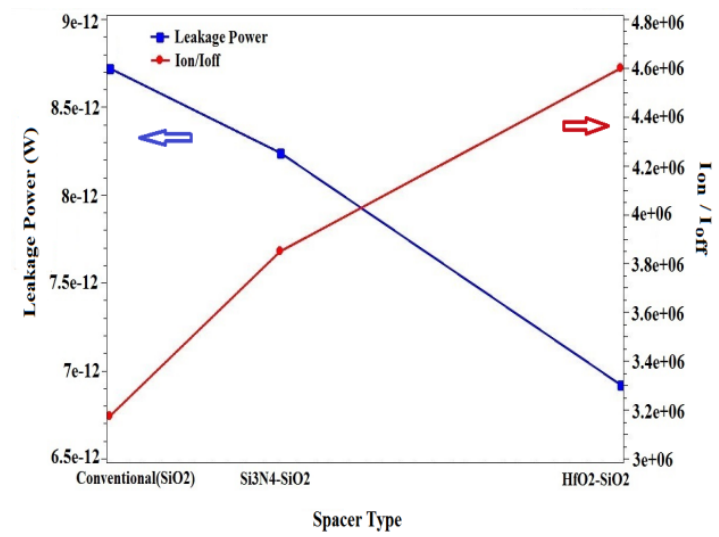

Figure 12: Effect of symmetric dual-k structure

Table 6 shows the effect of introducing asymmetric dual $\mathrm{k}$ spacer in wavy FinFET architecture. $28.25 \%$ reduction in leakage power is achieved by introducing asymmetric double dielectric spacer in wavy FinFET architecture

Table 6: Effect of asymmetric dual k spacer

\begin{tabular}{|l|l|l|l|l|}
\hline Structure & IOFF(A) & ION(A) & IoN/IOFF & Pleakage \\
\hline $\begin{array}{l}\text { Wavy } \\
\text { FinFET }\end{array}$ & $1.55 \mathrm{e}-11$ & $3.82 \mathrm{e}-05$ & $2.46 \mathrm{e} 06$ & $1.24 \mathrm{e}-11$ \\
\hline $\begin{array}{l}\text { Asymmetric } \\
\text { dual k }\end{array}$ & $1.11 \mathrm{e}-11$ & $3.76 \mathrm{e}-05$ & $3.38 \mathrm{e} 06$ & $8.89 \mathrm{e}-12$ \\
\hline
\end{tabular}

\section{Conclusion}

Since wavy FinFET is a hybrid structure of UTBFET(Ultrathin Body FET) and FinFET, it is found to be better than conventional FinFET in terms of drivability, integration density and area efficiency. The problems associated with wavy FinFET are increased leakage power and degraded SCE. This work could propose structural modifications of wavy FinFET using methods such as channel engineering, work function engineering, variation of isolation oxide thickness and spacer engineering to optimize the device for better performance. $\mathrm{I}_{\mathrm{ON}} / \mathrm{I}_{\mathrm{OFF}}$ ratios of optimized structures are given in Figure 13 and Percentage change in leakage power is shown in Table 7. It can be observed that these optimization techniques leads to reduction in leakage and improvement in performance of wavy FinFET.

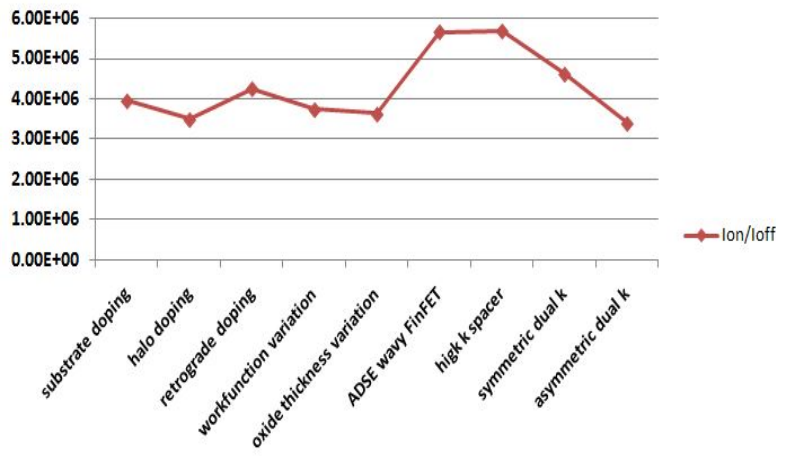

Figure 13: I $\mathrm{ON} / \mathrm{I}_{\mathrm{OFF}}$ in various optimization methods.
Table 7: Percentage change in leakage power and on current with optimization methods

\begin{tabular}{|l|c|}
\hline \multicolumn{1}{|c|}{ Methods } & $\begin{array}{c}\text { Value/Percentage } \\
\text { reduction in } \\
\text { Pleakage }\end{array}$ \\
\hline $\begin{array}{l}\text { Unoptimized Wavy } \\
\text { FinFET }\end{array}$ & $1.24 \mathrm{e}-11$ \\
\hline Substrate Doping & $40.39 \%$ \\
\hline Halo Doping & $30.39 \%$ \\
\hline Retrograde Doping & $43.75 \%$ \\
\hline Work function Engineering & $35.48 \%$ \\
\hline BOX thickness Variation & $32 . .25 \%$ \\
\hline Higk k spacer & $54.77 \%$ \\
\hline ADSE wavy FinFET & $61.35 \%$ \\
\hline Symmetric dual-k spacer & $44.19 \%$ \\
\hline Asymmetric dual-k spacer & $28.25 \%$ \\
\hline
\end{tabular}

\section{Acknowledgment}

This work was carried out by utilizing resources acquired by College of Engineering, Chengannur, through funded project granted by Department of Science Technology -India (DSTFIST Type-0).

\section{References}

This paper is an extension of work originally presented in 2016 IEEE International Symposium on Nanoelectronic and Information Systems [13]

[1] Gordon E. Moore, "Cramming more components onto integrated circuits", https://doi.org/10.1109/N-SSC.2006.4785860

[2] Tatjana Pesic-Brdanin, Branko L. Dokic, "Strained Silicon Layer in CMOS Technology", Electronics, vol. 18, no. 2, , 63-69, 2014. doi:10.7251/ELS1418063P

[3] M. Bohr, "The evolution of scaling from the homogeneous era to the heterogeneous era," in Proc. IEEE Int. Electron Devices Meeting, 2011, pp. 1.1.1-1.1.6. https://doi.org/10.1109/IEDM.2011.6131469

[4] Yuan Taur, "Fundamentals of Modern VLSI Devices"

[5] Y.-K. Choi et al., "Ultrathin-body SOI MOSFET for deep-sub-tenth micron era,"IEEE Electron Device Lett., vol. 21, no. 5, 2000, pages. 254-255. https://doi.org/10.1109/55.841313

[6] Jong-Tae Park et.al, "Multiple-Gate SOI MOSFETs:Device Design Guidelines", IEEE transactions on electron devices, vol. 49, no. 12, 22222229, 2002, https://doi.org/10.1109/TED.2002.805634

[7] W. Zhang et.al, “The ITFET: A novel FinFET-based hybrid device,"IEEE Trans. Electron Devices, vol. 53, no. 9, 2006, pages. 2335-2343.

[8] Hossain M. Fahad et.al, "Simulation Study of a 3-D Device Integrating FinFET and UTBFET", in press. https://doi.org/10.1109/TED.2014.2372695

[9] Overall Roadmap Technology Characteristics, ITRS,2013[Online].Available:http://www.itrs.net/links/2013ITRS/2013Tab les/2013ORTC_Detailed Table.pdf, accessed Nov. 25, 2014

[10] VisualTCAD Semiconductor Device Simulator Version 1.7.2 VisualTCAD User's Guide:Available :http://www.cogenda.com

[11] Kausik Roy, "Low voltage, low power VLSI subsystems". http://dx.doi.org/10.1036/007143786X

[12] Pankaj Pal et.al, "Investigation of Symmetric Dual-k Spacer Trigate FinFETs From Delay Perspective", IEEE transactions on electron Sdevices, vol. 61, 3579-3585, 2014. https://doi.org/10.1109/TED.2014.2351616

[13] Anju.C, Nisha Kuruvilla, AyoobKhan T E, Shahul Hameed T A, "Performance Analysis of Wavy FinFET And Optimization for Leakage Reduction”, IEEE Inis 2016. https://doi.org/10.1109/iNIS.2016.030 